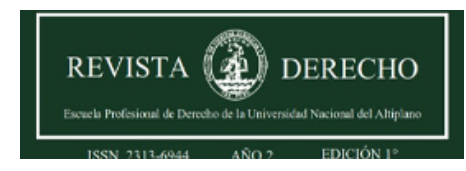

Revista de Derecho

ISSN: 2313-6944

ISSN: 2707-9651

revistaderecho@unap.edu.pe

Universidad Nacional del Altiplano

Perú

\title{
ANÁLISIS CRIMINOLÓGICO CRÍTICO: TRATAMIENTO PENITENCIARIO COMO MEDIO PARA LA CONCRECIÓN DE LA FINALIDAD DE LA PENA-CASO ANTAURO HUMALA (COVID 19)
}

Hancco Chipana, Miriam Rosmery; Arocutipa Arocutipa, Yeyset Nery

ANÁLISIS CRIMINOLÓGICO CRÍTICO: TRATAMIENTO PENITENCIARIO COMO MEDIO PARA LA

CONCRECIÓN DE LA FINALIDAD DE LA PENA-CASO ANTAURO HUMALA (COVID 19)

Revista de Derecho, vol. 6, núm. 1, 2021

Universidad Nacional del Altiplano, Perú

Disponible en: https://www.redalyc.org/articulo.oa? $\mathrm{id}=671870928007$

DOI: https://doi.org/10.47712/rd.2021.v6i1.112

\section{(c) (1)}

Esta obra está bajo una Licencia Creative Commons Atribución 4.0 Internacional. 
ANÁLISIS CRIMINOLÓGICO CRÍTICO: TRATAMIENTO

PENITENCIARIO COMO MEDIO PARA LA CONCRECIÓN DE LA FINALIDAD DE LA PENA-CASO ANTAURO HUMALA (COVID 19)

\title{
CRITICAL CRIMINOLOGICAL ANALYSIS: PENITENTIARY TREATMENT AS A MEANS FOR THE CONCRETION OF THE PURPOSE OF THE PENALTY-CASE ANTAURO HUMALA (COVID 19)
}

\author{
Miriam Rosmery Hancco Chipana \\ Universidad Nacional del Altiplano de Puno, Perú \\ Yeyset Nery Arocutipa Arocutipa \\ Universidad Nacional del Altiplano de Puno, Perú
}

DOI: https://doi.org/10.47712/rd.2021.v6i1.112

Redalyc: https://www.redalyc.org/articulo.oa?

$\mathrm{id}=671870928007$

Recepción: 02 Octubre 2020

Aprobación: 07 Enero 2021

Publicación: 10 Enero 2021

\section{Resumen:}

Debido a la situación en la que nos encontramos a raíz de los impactos de la Covid-19 en la sociedad peruana, las autoras realizan un análisis criminológico crítico del caso Antauro Humala a propósito del Covid-19 con el objetivo principal de demostrar el actual estado del sistema penitenciario a propósito de la pandemia, para que, en base a los planteamientos de la criminología critica justifiquen la importancia y la necesidad de un tratamiento penitenciario óptimo orientado a la concreción de la finalidad de la pena.

Además, en el marco de la criminología crítica y cautelar analizan la conjunción de los conceptos del sistema penitenciario, tratamiento penitenciario y finalidad de la pena con el objetivo secundario de demostrar en qué medida el denominado "óptimo tratamiento penitenciario" y consecuentemente la concreción de la finalidad de la pena beneficia a la sociedad peruana.

Palabras clave: Tratamiento Penitenciario, Caso Antauro Humala Covid-19, criminología crítica, política criminal, finalidad de la pena.

\section{AbStract:}

Due to the situation in which we find ourselves as a result of the impacts of Covid-19 on Peruvian society, the authors carry out a critical criminological analysis of the Antauro Humala case regarding Covid-19 with the main objective of demonstrating the current status of the penitentiary system regarding the pandemic, so that, based on the approaches of critical criminology, they justify the importance and need of an optimal prison treatment oriented to the realization of the purpose of the sentence. In addition, within the framework of critical and precautionary criminology, they analyze the conjunction of the concepts of the prison system, prison treatment and the purpose of the sentence with the secondary objective of demonstrating to what extent the so-called "optimal prison treatment" and consequently the realization of the purpose of the penalty benefits Peruvian society.

Keywords: Penitentiary Treatment, Antauro Humala Case Covid-19, critical criminology, criminal policy, purpose of the sentence.

\section{INTRODUCCIÓN:}

La criminología crítica apunta a la postulación de una política criminal, pero una política criminal alternativa, es decir, en base al estudio de la criminalidad de una sociedad y una economía determinada, postulando como respuesta a su estudio el abolicionismo del derecho penal. En medio de la emergencia sanitaria por el Covid - 19 se puso de relieve problemas que ya existían antes de la situación de emergencia, tanto en el sector económico, social y político, ante el arremetedor brote del Covid-19 las cárceles se hicieron oír en las protestas debido a las condiciones del hacinamiento carcelario y la excesiva población integrante, razón por la que el contagio del Covid-19 sería masivo y una bomba de tiempo que tarde o temprano arrasaría con todos. 
El tratamiento de los internos tiene que estar indefectiblemente ligado a su dignidad inherente y se le tiene que garantizar el acceso a los servicios indispensables, precisamente porque se encuentran en una relación de sujeción frente a la administración penitenciaria; sin embargo, esto parece todo un desafío debido a la marcada cultura de venganza del poder punitivo. Una muestra de ello se denota en el Expediente Nro. 01134-2020-PHC/TC el caso del interno Antauro Igor Humala Tasso, que se encuentra privado de su libertad en el establecimiento penitenciario-Ancón II y al contagiarse de la covid-19 solicita que sea trasladado a un establecimiento de salud para recibir tratamiento médico pedido que fue denegado; casos como el de Antauro, nos demuestran las condiciones inadecuadas e irrazonables a la que son expuestas la población penitenciaria, desde una mala infraestructura hasta las mínimas condiciones de salubridad.

El presente artículo desarrolla primigeniamente algunos alcances sobre la criminología crítica, postura adoptada para el desarrollo de la misma, se aborda también aspectos teóricos sobre la pena y su finalidad, derechos de los internos, la política criminal, el sistema penitenciario, el tratamiento penitenciario, para así, aterrizar estos conceptos en el caso materia de análisis - Antauro Humala-; posteriormente se fundamenta la necesidad brindar un adecuado tratamiento penitenciario, que se consagra como el medio por excelencia para logra la finalidad resocializadora de la pena; de la misma manera se aborda la problemática penitenciaria nacional y finalmente se fundamenta el objetivo de la función resocializadora de la pena y como ésta juega un papel elemental en la sociedad.

\section{GENERALIDADES}

\subsection{Criminología Crítica}

Desde que apareció la criminología crítica, aproximadamente en las décadas de los 60 y 70 , las cuestiones de la criminalidad fueron objetos de múltiples cuestionamientos; es decir, que esa tradicional forma de abordar el delito centrado en el estudio del hombre (delincuente) fue cortado de inmediato y la criminología crítica empezaba a comprender de manera diferente al fenómeno de la criminalidad.

Alessandro Barata en su obra Criminología Critica y Crítica al Derecho Penal refiriéndose a la criminología critica como nueva criminología señala que "La consideración del crimen como un comportamiento definido por el derecho, y el rechazo del determinismo y de la consideración del delincuente como un individuo diferente, son aspectos esenciales de la nueva criminología" (Baratta, 2004).

Por lo que la criminología crítica planteó científicamente la cuestión de la criminalidad, lo que significa que "ya no se dedica exclusivamente al hombre, sino también en el legislador, los rotuladores y los ejecutores de la norma, las denominadas agencias de control penal que enseña Zaffaroni” (Acosta Gallegos).

Por eso, es que la criminología crítica apunta a la postulación de una política criminal, pero una política criminal alternativa, es decir, en base al estudio de la criminalidad de una sociedad y en una economía determinada.

En lo que concierne al presente artículo sistema penitenciario - tratamiento penitenciario, son consideraciones de la criminología críticas, están dirigidas a una reforma epistemológica del sistema penitenciario, lo que quiere decir que no se trata nada más de una simple reforma a nivel legislativo, sino una reforma basada en hechos que acontecen en la realidad con observancia de los factores económicos y políticos.

1.2. La Pena y su finalidad según sus Teorías.

El poder punitivo citando a Zaffaroni siempre ha existido, solo que se ha cambiado constantemente de traje. Se tratará a groso modo sobre las teorías de las penas y su finalidad todo ello de acuerdo a el propósito que persiguen, existen: la teoría absoluta (retribucionista), las teorías relativas y la teoría mixta.

a) La teoría absoluta o retribucionista.

Según (Busato \& Montes Huapaya, 2009) esta teoría tiene sustento en la libertad ejercida por el hombre de decidir y realizar los actos que el desee, por el libre albedrio, no obstante todo acto será retribuido conforme 
a su proceder, mal por mal, la pena en ese sentido sería el pago o castigo que se le atribuye a un individuo conforme a su delito.

b) Las teorías relativas.

Mas que reprender una conducta con una pena, se buscó prevenir las conductas criminales, aun si es por intimidación o resocialización, las teorías relativas tienen como finalidad la prevención, ya sea general o especial:

$\S$ La prevención general: "Se buscaba prevenir la criminalidad a través de la intimidación o persuasión como instrumento idóneo, de ahí que se aplauda el incremento de las penas, para que de alguna u otra forma se reduzca la posibilidad de cometer un delito" (Busato \& Montes Huapaya, 2009). Sin embargo, esta postura resulta ineficaz debido a que en nuestro país la legislación funciona de acuerdo a la coyuntura y el incremento de las penas no logra que se reduzca la criminalidad, más por el contrario pareciera que las personas son indiferentes.

$\S$ La prevención especial: debido a la ineficacia de la intimidación lo que se busca es evitar en el individuo vuelva a incidir en cometer el delito (reincidencia) y se pretende que vuelva a la sociedad (Resocialización) esto sería una mejor forma de evitar la futura comisión de crímenes, labor difícil, porque se suele sellar a las personas que estuvieron en la cárcel, de ahí que autores como Zaffaroni se refieran a que los las personas privadas de su libertad son etiquetados situación que evita que pueda volver a insertarse a la sociedad por la desconfianza que tienen de ellos y quizá hasta temor, negándole un trabajo o rechazándolos, razón que los obliga a incidir y volver a la vida delictiva. Además de que las políticas de la criminalidad al menos en nuestro país no logran brindar las condiciones resocializadoras (educación, salud, etc.)

c) La teoría Mixta:

La finalidad que se persigue es tanto retribuir el daño causado como promover la resocialización a través de políticas públicas y a esto se añade la protección de los bienes jurídicos. Este último debido a que no solo se le puede buscar un castigo o al menos ese no es el objetivo sino las protecciones de valores supremos.

1.3. Derechos de los internos

La población carcelaria (investigados y condenados) no dejan de tener la calidad de seres humanos, por tanto, en el marco del principio de la dignidad, estos continúan manteniendo todos sus derechos excepto el de la libertad y aquel que haya sido limitado por la sentencia -en cada caso concreto- por lo que el Estado adquiere el papel de garante de estos derechos, “(...) el Estado tiene una posición de garante respecto a los derechos de las personas privadas de libertad, cuando las condiciones de detención resultan incompatibles con la dignidad humana y se traducen en la ejecución de verdaderas penas ilícitas" (Gusis, y otros, 2020)

Conforme señala la norma suprema del Estado la pena privativa de libertad tiene como fin la reeducación y la reinserción del penado a la sociedad, “(...) en tal virtud estas dejan de ser un fin en sí mismas, para constituirse en un instrumento o medio de cambio de aquellos ciudadanos que vulneran el pacto social plasmado en las leyes penales" (Castillo Torres). Así, también el Tribunal Constitucional estima que "la pena y el régimen penitenciario (resocialización, readaptación y rehabilitación) son expresiones de dignidad, por lo que constituyen un límite para el legislador penal" (Caso Marcelino Tineo Silva y más de 5000 de ciudadanos, 2003)

\subsubsection{Marco Normativo Nacional}

En la legislación nacional, es la Constitución Política del Perú que regula lo concerniente a la protección de los derechos humanos, el artículo 1 señala "la defensa de la persona humana y el respeto de su dignidad son el fin supremo de la sociedad y el estado"; además, en el artículo 2 se enumera los derechos "de tal manera que no excluya los demás que la Constitución garantiza, ni otros de naturaleza análoga o que se fundan en la dignidad del hombre (...)" (INPE, 2018).

También en el Art. 139 inciso 21 de la Constitución nacional enmarca que es uno de los principios es "el derecho de los reclusos y sentenciados de ocupar establecimientos adecuados”, lo cual implica según (Castillo Torres) seis los deberes del estado: a) evitar los abusos físicos y psíquicos, b) proteger la salud de los reclusos, 
c) permitir el sostenimiento de la relaciones familiares, d) facilitar la consecución de los fines de la pena, e) contar con el personal idóneo y f) efectuar una adecuada clasificación y separación entre internos.

De lo enfatizado, por el maestro (Castillo Torres), se puede advertir que uno de los deberes principales del estado es el de proteger la salud de los reclusos, lo que significa que todo establecimiento penitenciario debe procurar que los internos gocen de una buena salud física y mental, por lo tanto "el derecho a la salud proyecta como conservación y restablecimiento de ese estado. Implica, por consiguiente, el deber de que nadie, ni el Estado ni un particular, lo afecte o menoscabe" (Exp. N¹422-2002-HC).

\subsubsection{Marco Normativo Internacional}

En el ámbito internacional, los derechos humanos se encuentran regulados por instrumentos emitidos por el sistema universal como la Declaración Universal de los Derechos Humanos y la del sistema americano mediante la Convención Americana de los Derechos Humanos. En materia de ejecución penal, la Asamblea General de las Naciones Unidas adopta un conjunto de declaraciones, principios y reglas orientadoras, mediante resoluciones, teniendo como una de las principales características: "considerar que la pena tiene un propósito resocializador, es decir, rehabilitar a la persona privada de su libertad para evitar su reincidencia" (INPE, 2018).

El Instituto Nacional Penitenciario, mantiene la "rectoría del Sistema Penitenciario Nacional y competencia en la ejecución de las medidas privativas de libertad, la pena privativa de libertad efectiva y suspendida, penas limitativas de derechos, las medidas alternativas a la pena privativa de libertad, con la finalidad de alcanzar la reinserción social” (INPE, 2018).

1.4. La Política Criminal y el Sistema Penitenciario

En sentido amplio se entiende por política criminal como el "conjunto de objetivos que sustentan las decisiones estatales tomadas para hacer frente a la criminalidad" (Grandez Rojas, 2017), y conceptualizándolo se entiende como el conjunto de “(...) conocimientos y experiencias que se interrelacionan para prevenir y contrarrestar los riesgos y conductas delictuales de la forma más eficaz posible, garantizando derechos fundamentales y que se plasman a través de normas analizadas y promulgadas por el legislador nacional" (Grandez Rojas, 2017).

Como fines de la política criminal según (Grandez Rojas, 2017) tenemos los siguientes: a) en primer lugar, el sistema penitenciario debe ser eficaz en la lucha contra la criminalidad, lo que significa llevar la criminalidad a niveles que permitan aún la convivencia social y b) la segunda finalidad de la política criminales es mantener el respeto de las garantías de los ciudadanos frente al ejercicio de la potestad punitiva.

Grandez Rojas, señala también que existe tres tipos de política criminal, la política criminal penal, la política criminal procesal penal y la política criminal penitenciaria; de los cuales para efectos de este trabajo desarrollaremos de manera breve la política criminal penitenciaria.

a) Política criminal penitenciaria

La política criminal penitenciaria “(...) se ejecuta en ejecución de sentencia, es decir el cumplimiento de las penas propiamente dichas ejecutadas por el ente encargado, es decir, el Instituto Nacional Penitenciario - INPE” (Grandez Rojas, 2017).

La política criminal es el direccionamiento político en el ámbito de la población carcelaria, esta orientada a la organización, resguardo, aseguramiento de lineamientos, etc.

En el cumplimiento de una pena -por citar un ejemplo- la política criminal "se aplica a través del endurecimiento para obtener los beneficios penitenciarios, siendo que las normas han cambiado sobre ello para ciertos delitos que incluso se le ha eliminado, es decir que no tienen estos beneficios penitenciarios, así también esta política se refleja con la emisión de normas de otros dispositivos legales de descongestionar los establecimientos penitenciarios como leyes de grilletes electrónicos, la conversión de penas en ejecución, entre otros" (Grandez Rojas, 2017).

b) Sistema penitenciario 
El sistema penitenciario (SP) es el conjunto de normas que regla o regula el funcionamiento interno de las prisiones de un determinado país, y, que están direccionadas a una determinada concepción respecto a los fines que debe lograr la privación de la libertad.

Un concepto concurrente al SP es el de las cárceles, el cual puede concebirse como “(...) un edificio o un complejo de edificios en donde un delincuente debe cumplir una pena restrictiva o limitativa de su libertad de movimiento" (Cárcamo, Guarnizo, Mendoza, Pajares, \& Vignolo, 2015). Teóricamente “(...) con la finalidad de aislarlo para, a través de distintos mecanismos que lleva a cabo la administración penitenciaria, resocializarlo y, posteriormente, reincorporarlo en la sociedad" (Cárcamo, Guarnizo, Mendoza, Pajares, \& Vignolo, 2015).

En nuestro país la entidad encargada de dirigir y controlar todo el sistema penitenciario es el Instituto Nacional Penitenciario (INPE) organismo público descentralizado del Ministerio de justicia, que goza de personería jurídica de derecho público, entidad que según su Reglamento de Organización y Funciones en su artículo $4^{\circ}$ refiere que tiene como objetivo dirigir y controlar técnica y administrativamente el Sistema Penitenciario Nacional, asegurando una adecuada política penitenciaria, tendiente a la resocialización de interno. Así mismo del artículo $5^{\circ}$ de dicho reglamento se puede advertir que está encargada del tratamiento penitenciario, es una de sus funciones. En la actualidad, el INPE administra 67 de los 84 establecimientos penitenciarios existentes a la escala nacional, distribuidos en ocho regiones del país.

1.5. El Código de ejecución Penal y el tratamiento penitenciario

Como ya lo señalamos anteriormente en nuestro país el ente encargado del tratamiento penitenciario es el INPE, institución que asegura el cumplimiento de lo dispuesto por el Código de Ejecución Penal (en adelante CEP), publicado el 02-08-91, para el tratamiento de los internos, sentenciados y procesados, a nivel nacional.

Siendo así, una de las funciones de la INPE la convergencia y la articulación de la población penitenciaria; es decir, sobre personas con medidas de detención o prisión preventiva, así como de personas sentenciadas a pena privativa de libertad o comúnmente se les suele llamar internos; ya sea, bajo la condición jurídica de procesado (que se encuentren aun en etapa de investigación o juzgamiento) o bajo la condición jurídica de sentenciados (que se encuentran con sentencia judicial firme). Por lo tanto, para que se cumpla con los fines de la pena, los establecimientos penitenciarios deben de ser los más óptimos posibles, adecuados y estar acorde con el fin resocializador perseguido, de lo contrario no se estaría logrando el fin de la pena a la que se quiere llegar.

El objetivo de la Ejecución Penal está previsto en el Art. II del TP del CEP, que recoge los conceptos de reeducación, rehabilitación y reincorporación del penado a la sociedad, doctrinalmente pueden resumirse en el de resocialización del interno. Igualmente, la vigente Constitución Política de 1993 y el CP, recogen este principio.

El CEP al fijar “(...) finalidad resocializadora de la ejecución penal, el interno ya no es considerado una persona eliminada de la sociedad, sino que continúa formando parte de ella, como miembro activo. El penado conserva así todos los derechos reconocidos por las normas jurídicas vigentes, con excepción, naturalmente, de aquellos cuya privación o limitación constituya precisamente el contenido de la pena impuesta" (Castro Vadillo, 2009).

Así mismo, del artículo $60^{\circ}$ del Código de Ejecución Penal se puede advertir que el tratamiento penitenciario, es el conjunto de actividades directamente dirigidas a la consecución de la resocialización (a lograr la reeducación, rehabilitación y reincorporación del interno) por lo que se puede afirmar que el tratamiento es el elemento esencial del Sistema Penitenciario. El CEP desarrolla el tratamiento mediante el sistema progresivo moderno, siendo sus objetivos: la reeducación, la rehabilitación y la reincorporación del interno a la sociedad.

En el CEP se regulan los derechos del interno, el régimen penitenciario, la clasificación de los establecimientos penitenciarios, el tratamiento penitenciario, se brinda también especial importancia a la educación, así como a proteger y velar por la vida y la salud del interno. 


\section{DERECHO A LA SALUD DEL INTERNO. CASO ANTAURO HUMALA}

El Estado tiene el deber de garantizar que las condiciones de las prisiones sean adecuadas a la dignidad de los internos, prevenir que estos padezcan tratos crueles, inhumanos o degradantes, sin embargo, existe una brecha entre el ser y el deber ser.

La posición de garante del Estado en el sistema penitenciario es que tiene el deber de garantizar el ejercicio pleno de los derechos y libertades a las personas privadas de libertad debido a que se encuentran en custodia del Estado y en especial el derecho a la salud entendida como el más alto grado de bienestar físico, mental y social y que tiene que ser garantizado por el Estado y las autoridades competentes deben de facilitar sus instalaciones y acondicionarlas razonablemente para brindar los servicios idóneos a la población penitenciaria.

"En este sentido, si una persona fuera detenida en buen estado de salud y posteriormente, muriera, recae en el Estado la obligación de proveer una explicación satisfactoria y convincente de lo sucedido"(Corte IDH. Caso Juan Humberto Sánchez Vs. Honduras. Excepción Preliminar, Fondo, Reparaciones y Costas. Sentencia, n.d.) Si ha de darse el supuesto planteado el Estado tendrá que explicar, probar y desvirtuar las alegaciones en su contra.

En relación al caso materia de análisis, el 31 de marzo de 2020, Antauro Igor Humala Tasso en adelante Antauro, interpone demanda de hábeas corpus correctivo en contra de Edith Ramón Chocano directora del establecimiento penitenciario Ancón II, peticionado que se le traslade a un establecimiento de salud o en su defecto a un Hospital Militar por ser ex oficial del ejército peruano, después de presuntamente haber dado positivo a contagio del Covid - 19, tras someterse a un examen de descarte en el centro odontológico del establecimiento penitenciario; lo cual representa un grave riesgo para su vida y salud, debido a que ya presentaba los primeros síntomas del virus, la defensa técnica señala también que Antauro estaría siendo objeto de un tratamiento carente de Razonabilidad y Proporcionalidad.

El 02 de abril de 2020, Antauro solicita que se le practique una prueba de descarte por presentar dolor en la garganta, en virtud a ello, el mismo día el Juzgado de Investigación Preparatoria de Puente Piedra solicita informes sobre las medidas adoptadas por el INPE para evitar contagios del Covid - 19 en los internos. El procurador público del INPE responde señalando que en el establecimiento penal aún no hay contagiados y que se han tomado las medidas de prevención y contención, sugiriendo que la demanda sea declarada improcedente.

El 09 de abril de 2020, el Juzgado de Investigación Preparatoria declaró improcedente la demanda, tras considerar que no ha existido menoscabo alguno en las condiciones en las que se desarrolla la restricción del ejercicio de la libertad personal, pues no se le ha negado tratamiento médico alguno a Antauro, señala además el Juez que Antauro en la demanda interpuesta no ha sido contagiado con el Covid-19.

El 23 de abril de 2020, la defensa técnica de Antauro, amplía su pretensión en los siguientes términos: a) segunda pretensión principal: disponer la variación de la medida de prisión efectiva dictada en contra del favorecido, por la medida coercitiva de detención domiciliaria; b) primera pretensión accesoria: que el INPE, en resguardo de la vida del favorecido y para evitar el contagio del COVID-19, disponga el traslado a su domicilio, a efectos de que en dicho lugar cumpla con el aislamiento social obligatorio dispuesto en el Decreto Supremo 044-2020-PCM; y c) segunda pretensión accesoria: en cumplimiento de las pretensiones antes mencionadas, la permanencia en su domicilio se mantenga.

El 28 de abril de 2020, Antauro presenta un escrito indicando haber dado positivo al contagio del Covid-19, por lo cual solicita que se le brinde tratamiento hospitalario. Sin embargo, el Procurador Público del 29 de abril del mismo año, afirma que se ha garantizado el derecho a la salud de Antauro porque su condición es clínicamente estable.

El 02 de mayo de 2020, la Sala Mixta de Emergencia de los Distritos de Ancón, Santa Rosa y Puente Piedra de la Corte Superior de Justicia de Puente Piedra - Ventanilla, revoca la resolución apelada y reformándola, 
declara infundada la demanda, señalando que Antauro se encuentra estable, con medicación y supervisión médica.

El 18 de junio de 2020, el Pleno de Tribunal Constitucional integrado por los señores magistrados Ledesma Narváez, Ferrero Costa, Miranda Canales, Blume Fortini, Ramos Núñez y Sardón de Taboada, resuelve declarar infundada la demanda de habeas corpus en el extremo referido a no ser objeto de un tratamiento carente de razonabilidad y proporcionalidad, respecto a la forma y condiciones en que el favorecido cumple su pena privativa de libertad y solicita tratamiento en un centro hospitalario; y declarar improcedente la demanda de habeas corpus en lo demás que contiene. En base a las siguientes consideraciones: el Oficio Nro. 236-2020-INPE-18-244-D, emitido por la demandada Edith Ramón Chocano en su calidad de directora del Establecimiento Penitenciario - Ancón II, que señala que Antauro se encuentra en un ambiente destinado para pacientes con Covid - 19, espacio que cuenta con ambiente privado para cada interno, con baño, lavadero y ducha personal, además porque Antauro se encuentra clínicamente estable, conforme al Informe Médico 019-2020-INPE/18-EPM.ANCON II-SDSP de fecha 29 de abril de 2020. Afirmando así el Tribunal Constitucional que las medidas adoptadas por el INPE han sido razonables y proporcionales.

2.1. Ancón II - Antauro Humala, ¿La excepción a la regla?

La decisión tomada por el T.C. en el caso desarrollado en líneas anteriores-Antauro Humala a propósito de la Covid 19- trae consigo la necesidad de abordar y reflexionar sobre la actuación del INPE y las políticas que ha estado implementando para poder la propagación del virus, en aras de resguardar la vida y salud de los internos.

De los fundamentos del supremo interprete de la constitución, se podría llegar a inferir que en nuestro país las políticas dirigidas al control de la pandemia en el sistema penitenciario han sido muy acertadas y que se ha actuado oportunamente por lo que la situación estaría completamente controlada, así mismo en el caso concreto-Antauro COVID 19- la defensa del INPE señalaba que se ha implementado adecuadamente los sectores de aislamiento y que la institución está preparada para brindar atención a los que llegaran a contagiarse, sin embargo este panorama esta muy lejano a la realidad carcelaria de los 68 penales de nuestro país, por lo que podemos afirmar que la decisión del TC, está fundamentada en circunstancias que difieren de las "óptimas condiciones en las que se pudiera brindar atención médica en casos de contagios" y que está más cercana a las circunstancias que acompañaron el asunto de fondo, como el que el recurrente ya haya superado el virus, la "repentina y circunstancial" ampliación y/o acumulación de las pretensiones y por la figura del recurrente- al tratarse de un personaje muy mediatizado- es que el T.C haya fallado en su contra.

En ese sentido, resulta erróneo considerar las supuestas excelentes condiciones en las que se encuentra el establecimiento penitenciario Ancón II - como un indicador de la realidad carcelaria peruana; por el contrario, hasta junio del 2020 más de 221 internos han fallecido y hasta agosto de este año se han registrado 12294 internos infectados; además, durante los meses de junio y julio se han registrado diversos motines como el del Penal Castro Castro que cobro la vida de 9 internos tras el intento de huir.Y más aún cuando dentro de las personas privadas de libertad, existen grupos de especial protección, dado que el Covid 19 puede ocasionar graves estragos en su salud, por lo que, se exige por parte del Instituto Nacional Penitenciario (INPE) y del Estado una respuesta articulada en su conjunto. Sin embargo, hasta el momento no se conocen de planes de prevención y atención enfocados en sus casos. Entre los grupos más vulnerables tenemos: a) las personas adultas mayores, ya que, "la ancianidad incrementa el riesgo de presentar enfermedades físicas y mentales que pueden colocar a la persona en situación de fragilidad o dependencia (...)” (Defensoría del Pueblo, 2020), hasta diciembre de 2019, 4761 adultos mayores de 60 años ocupan las cárceles, siendo por tal motivo urgente contar con planes de prevención y atención contra el CODIV-19. Otro grupo vulnerable son b) los niños y niñas que viven en las cárceles, “(...) la mayoría de los niños y niñas no contaban con ambientes especiales alejados del resto de la población para pernoctar, pues compartían las celdas para dormir con sus madres y demás internas." (Defensoría del Pueblo, 2020), c) los más de 11536 internas o internos 
que adolecen enfermedades crónicas entre tuberculosis, VIH-SIDA, diabetes, hipertensión arterial, cáncer; población de alto riesgo frente a un posible contagio del coronavirus. Por tanto, es obligación del Estado no desatender la salud de la población carcelaria en especial en la lucha contra la COVID 19.

Si de por si concretizar la finalidad de la pena en nuestro país parece ser una labor que esta muy alejada de las verdaderas capacidades del mundo carcelario, la pandemia al menos mínimamente ha actuado en la sociedad como un reflector que ilumina la no novedosa crítica situación del sistema penitenciario, sistema que lejos de otorgar un tratamiento penitenciario orientado al deber ser - la resocialización - demuestra deficiencias gubernamentales, presupuestales y sociales.

\section{LA REALIDAD PENITENCIARIA PERUANA}

No es novedad que uno de los problemas mas latentes en nuestro país, es la crisis del sistema penitenciario, situación crítica acompañada de factores que impiden concretizar el cometido del régimen penitenciario, de la pena o de la ejecución penal. Uno de los factores, sino el mas importante, es el hacinamiento, problemática que se posiciona como la matriz de otros factores impeditivos, como las fallas de los mecanismos de control y vigilancia interna, deficiencia en la atención médica, ausencia de programas efectivos relacionados con la educción, etc. Abordemos pues brevemente la situación peruana respecto a este problema:

3.1. Hacinamiento

La Comisión Interamericana de Derechos Humanos, en su Informe "Sobre los Derechos Humanos de las Personas Privadas de Libertad en las Américas” del 2011 citado por la (Defensoría del Pueblo, 2020) indica que "El hacinamiento puede llegar a constituir en sí mismo una forma de trato cruel, inhumano y degradante, violatoria del derecho a la integridad personal y de otros derechos humanos reconocidos internacionalmente (...)".

Según Fuente especificada no válida. "la población del sistema penitenciario al mes de febrero 2020 es de 129,115 personas. De ellos, 96,870 se encuentran en establecimientos penitenciarios al tener mandato de detención judicial o pena privativa de libertad efectiva, mientras que 32,245 personas asisten a establecimientos de medio libre al haber sido sentenciados a penas limitativas de derechos, dictaminado medidas alternativas al internamiento, o liberados con beneficio penitenciario de semilibertad ó liberación condicional. (p. 4)

"El mes de febrero, la diferencia entre la capacidad de albergue y la población penal es de 56,733 internos que representa el $141 \%$ de la capacidad de albergue, esto quiere decir que esta cantidad de internos no tendría cupo en el sistema penitenciario" Fuente especificada no válida.. A continuación, mostramos un cuadro que evidencia la cantidad de sobrepoblación que existe en los establecimientos penitenciarios del país:

TABLA 1

Situación Actual de la Capacidad de Albergue, Sobrepoblación y Hacinamiento según Oficina Regional

\begin{tabular}{|c|c|c|c|c|c|c|c|}
\hline & Oficinas Regionales & Capacidad de Albergue (C) & Población Penal (P) & \% Ocupación & Sobre Población (S=P-C) & \% Sobre Población (\%S) & Hacinamiento $(\% \mathrm{~S}>\mathbf{2 0 \%})$ \\
\hline & FALES & 40,137 & 96,870 & $241 \%$ & 56,733 & $141 \%$ & SI \\
\hline 1 & NORTE - CHICLAYO & 6,514 & 18,071 & $277 \%$ & 11,557 & $177 \%$ & SI \\
\hline & $\begin{array}{l}\text { LIMA - LIMA } \\
\text { LIM }\end{array}$ & 17,341 & 45,784 & $264 \%$ & 28,443 & $164 \%$ & SI \\
\hline 3 & SUR - AREQUIPA & 1,252 & 4,336 & $346 \%$ & $\begin{array}{l}20,41,0 \\
3,084\end{array}$ & $246 \%$ & SI \\
\hline 4 & CENTRO - HUANCAYO & 2,064 & 7,321 & $355 \%$ & 5,257 & $255 \%$ & SI \\
\hline & ORIENTE - HUANUCO & 3,240 & 6,807 & $210 \%$ & 3,567 & $110 \%$ & SI \\
\hline $\begin{array}{l}5 \\
6\end{array}$ & SUR ORIENTE - HUÁNUCO & 2,918 & 5,943 & $204 \%$ & 3,025 & $104 \%$ & SI \\
\hline 7 & NOR ORIENTE - SAN MARTIN & 5,352 & 5,982 & $112 \%$ & 630 & $12 \%$ & NO \\
\hline 7 & $\begin{array}{l}\text { ALTIPLANO - PUNO } \\
\text { PUN }\end{array}$ & 1,456 & 2,626 & $180 \%$ & 1,170 & $80 \%$ & SI \\
\hline
\end{tabular}




\author{
Oficina General de Infraestructura - INPE \\ Nota. Elaboración: INPE/Unidad de Estadística (INPE, 2020)
}

Del cuadro elaborado por la INPE, se advierte claramente que existe una sobrepoblación del aforo máximo para albergar internos en los diferentes establecimientos regionales que existen en el país; es decir, que cuando se excede el aforo máximo de internos se conoce como lo comúnmente lo denominan sobrepoblación o hacinamiento penitenciario. Por lo que no se cumple representa una barrera para concretar la finalidad de la pena, ya que los internos de nuestro país no se encuentran en las condiciones adecuadas para recibir un verdadero tratamiento penitenciario; porque, para lograr tal finalidad de la pena (resocialización, readaptación y rehabilitación) se deben de tener establecimientos adecuados en cuanto a infraestructura, en cuanto a la asistencia en educación, salud, etc.

\title{
4. DE VICTIMARIO A VÍCTIMA, POLÍTICA PENITENCIARIA EN PRO DE LA CONCRECIÓN DE LA FINALIDAD DE LA PENA
}

Cuando se realiza el estudio de las 'víctimas', desde una perspectiva criminológica y victimológica, generalmente se habla de tres 'procesos de victimación': La victimación primaria, que es la que se comete a las víctimas directas e indirectas del delito. La victimación secundaria, que es la que vuelven a sufrir las víctimas del delito durante la investigación policial y durante el proceso judicial. La victimación terciaria, que es la que sufre el victimario a través del proceso judicial y durante el cumplimiento de su condena.

En lo que atañe a tema abordado -la victimación terciaria- el sujeto pasivo de la victimación terciaria es el victimario. Entonces esta debe ser entendida como la victimación que sufre el agresor durante el proceso judicial y el cumplimiento de su condena, respecto al cumplimiento de las penas, el profesor (Pérez Guadalupe, 2009) "Por más que el sentido de la reclusión penitenciaria, al menos en el discurso, sea la reeducación, la readaptación y la resocialización del delincuente, es bien sabido que los efectos reales del encarcelamiento son totalmente contrarios. Incluso muchas veces, la cárcel se convierte en un eficaz agente criminógeno. El discurso para las galerías, y para la sociedad en general, dista mucho de las verdaderas alternativas de resocialización que se brindan en las cárceles. Incluso se habla de unos 'objetivos ocultos' de la cárcel que son muy diferentes a los que aparecen en los códigos y reglamentos y que serían cumplidos al pie de la letra en muchos sistemas penitenciarios".

Las condiciones victimizantes se agravan también debido a las pésimas condiciones de la vida intracarcelaria, proceso de victimación que contienes situaciones victimizantes como: Hacinamiento y falta de una clasificación penitenciaria adecuada. Deficiente sistema de higiene y salubridad, Precarios e insuficientes lugares de atención médica, Fuerte sentimiento de 'prisionización', Dominio y abuso de unos presos sobre otros, Tráfico y consumo de estupefacientes Insuficiente o desbalanceada dieta alimenticia Insuficiente personal y tratamiento psicológico Insuficientes alternativas de formación educativa y laboralEstigmatización social de los presos y sus familias, etc.

Estos factores no solamente conculcan los derechos de los internos, sino que también impiden la efectivización de la finalidad resocializadora de la pena.

Por otro lado, estas situaciones victimizantes que atañen a la totalidad de los presos de las cárceles en donde se presentan, podemos mencionar ciertas situaciones o grupos particulares que son víctimas de discriminaciones especiales por parte del poder judicial y de la institución penitenciaria. Por ello existen sectores sociales que son los más propensos a caer en manos de la justicia y de las cárceles, tal es el caso de "La criminalización de ciertos sectores económicos" que usualmente son los más desfavorecidos y son los llamados por excelencia a ocupar las cárceles; "La criminalización de ciertos grupos étnicos, religiosos o nacionales", basta por ejemplo comparar el porcentaje de negros y latinos en las cárceles de Estados Unidos, que no guarda ninguna relación con el porcentaje de esos grupos en la población de dicho país. La criminalización de los drogodependientes, al respecto el ex ministro de Justicia de nuestro País (Pérez Guadalupe, 2009) indica 
que "(...) un adicto de clase alta va a una clínica privada para desintoxicarse mientras que un adicto de clase baja va a la cárcel a cumplir condena. Los llamados 'drogo delincuentes' (los que roban para consumir droga) son doblemente criminalizados ya que, en primer lugar, no deberían ir a una cárcel, sino a un centro de tratamiento o rehabilitación; y, en segundo lugar, porque en la cárcel tampoco se libran del consumo de drogas e incluso llegan a prostituirse para poder conseguir la droga de la cual dependen y que, paradójicamente, los llevó a la cárcel”.

Muchas veces se da el caso de presos que entran en prisión por otros delitos y en la misma cárcel (por las circunstancias especiales que pasa el interno y por la facilidad de conseguir estupefacientes) es donde se enganchan a la droga; en estos casos, que no son pocos, la Institución penitenciaria no solo no logró 'resocializar' al interno, sino que lo 'de socializó' más aún.

\subsection{Penas ilícitas}

Según (Zaffaroni, 2020) las penas pueden ser lícitas o ilícitas, considerando a estas últimas como penas crueles, inhumanas y denigrantes; es decir, estas penas ilícitas son penas que cometen los Estados a través de los funcionarios públicos (agencias ejecutivas en palabras del profesor). Estas penas como lo dice Zaffaroni van más allá de las sanciones formales que ha previsto el legislador como reacción a la comisión de delitos, ya que el castigo no solo termina con el encarcelamiento, sino que ha ello se le aúna componentes ilegítimos, como ponerlos en riesgo de contagio del Covid - 19 ha falta de medidas adecuadas de prevención. Por tanto, no podemos negar que la situación en las prisiones del país es espantosa, existe sobrepoblación penitenciaria, lo que pone en riesgo la vida y la salud de los internos, lo cual no es más que una pena ilícita cometidos contra los internos.

\section{EL FIN DE LA FINALIDAD DE LA PENA, ALCANCES DE LA CRIMINOLOGÍA CRÍTICA}

Para Zaffaroni la resocialización se trata de un proceso de "personalización" el cual, a partir de un trato humano y lo menos degradante posible, tiende a disminuir el nivel de vulnerabilidad del condenado frente al sistema penal, dotándolo de los medios necesarios como para que pueda tomar conciencia de su rol y salirse del estereotipo selectivo del poder punitivo.

El prefijo re- significa repetición, "volver a", en este caso supone un segundo intento de socialización. Con la resocialización se da la transformación hacia unas condiciones de integración mejores que antes, se ofrece la posibilidad de una participación plena en la sociedad y de desarrollar los derechos de los ciudadanos en todas las facetas de la vida en sociedad.

"Apoyándose en estos ideales el principio resocializador transcurre por un proceso en el que van aumentando las perspectivas de cara a conseguir un sistema penitenciario que logre la efectiva resocialización de los delincuentes orientado al futuro, dirigido a la comunidad y al beneficio social". (Martínez Blanch, 2014)

En el caso peruano, por ejemplo, esto se ve reflejado en que 1,442 internos están sentenciados a pena privativa de libertad entre 31 a 35 años, existen 1,152 internos con penas de cadena perpetua lo que representa solo el $1 \%$ de la población y el resto inevitablemente abandonara los penales, y de no existir un adecuado tratamiento penitenciario, los ex internos "des socializados" continuaran afectando la estabilidad social de nuestro país en caso suceda lo contario, eso es que se efectué un adecuado tratamiento penitenciario, y los ex internos abandonen los penales cuando se encuentren resocializados, y encontraran una sociedad que seguirá siendo la cuna de la delincuencia y configurada como una población criminal, esta labor (resocialización) no tendrá mayor proyección, generando así un circulo vicioso que si no se ataca desde el origen, no podrá terminar.

Ante ello, la consolidación de la criminología crítica desde de la década de los 70 del siglo pasado representa el momento de superación de una perspectiva micro hacia una comprensión macro criminológica en el 
interior de las ciencias criminales. Esto es, que la criminología crítica planteó científicamente la cuestión de la criminalidad, lo que significa que "ya no se dedica exclusivamente al hombre, sino también en la sociedad en su conjunto, el legislador, los rotuladores y los ejecutores de la norma, y a lo que zaffaroni denomina agencias de control penal.

Por lo que la criminología critica plantea que aquellos programas de resocialización que sigan una metodología únicamente de carácter psicológico y solamente consideren al individuo, no podrán funcionar, siendo necesario tener en cuenta a la sociedad y sus estructuras, ya que son estas las que deben cambiar y así dejar de ser la causa de que se produzcan determinados tipos de delitos.

La criminología crítica o nueva criminología lo que hace es analizar a la sociedad situándola como el origen, como generadora de desigualdades que provocan la existencia de delincuentes. De ello puede desprenderse la idea de que la criminalidad es proporcional a la desigualad social, cuanta más marginalidades más delincuentes.

La aportación que supone para la criminología sería la nueva idea sobre la causa del delito, no solamente es asunto del delincuente y de su voluntad, sino también de la estructura social y económica que provoca la conculcación de libertades mediante las normas que elabora la clase que ostenta el poder.

Entonces, "antes de hablar de educación y de reinserción es, pues, menester hacer un examen del sistema de valores y de modelos de comportamiento presentes en la sociedad en que se quiere reinsertar al detenido. Tal examen no puede, creemos, sino llevar a la conclusión de que la verdadera reeducación debería comenzar por la sociedad antes que, por el condenado, ello significa que "el instituto penal no puede realizar su objetivo como institución educativa ya que esta función corresponde exclusivamente a la sociedad” (Baratta, 2004).

\section{CONCLUSIONES}

Primero: El coronavirus está dejando en la sociedad una serie de secuelas que afectan a todos los sectores sociales y definitivamente no nos encontrábamos preparados para afrontar la situación; la pandemia nos abrió los ojos ante la cruda realidad peruana, en cuanto atañe al presente artículo el ámbito penitenciario se encontraba colapsado antes de la covid-19, y como era de esperarse la crisis del sistema penitenciario se tornó incontenible. La situación de excepcionalidad que estamos viviendo representa un momento trascendente en la vida nacional, por lo que debemos lograr que esta tragedia nacional que ha desnudado la actuación increíblemente ineficiente de los gobiernos de turno represente una oportunidad de cambio, utilizando las lecciones que nos está dejando la covid-19 para lograr un cambio sostenible en la sociedad.

En nuestro país existe una convergencia legal en cuanto a la delimitación de la finalidad resocializadora de la pena, no obstante, estos grandes avances legislativos no son más que previsiones abstractas y que existe un lucha constante pero obstaculizada por factores externos, factores que dificultan el deber ser, la realidad no demuestra esta confluencia de los instrumentos legales, por lo que la concreción dependerá de la dotación debida de presupuesto al sistema penitenciario, lo que no implica establecer una secuencia prelatoria o de preferencias con otros sectores ( educación, salud, etc.) esta acción encuentra su justificación en la generación de un beneficio colateral: Por un lado asegurará un trato humano y libre de tortura a los internos lo cual a sus vez generará la optimización de condiciones para brindar satisfactoriamente el tratamiento penitenciario y consecuentemente concretar la finalidad de la pena, por otro lado, significará también un beneficio para la sociedad, beneficio representado como una manifestación de seguridad ciudadana, que a la vez, contribuye a garantizar la paz, tranquilidad y a reducir o neutralizar la criminalidad y delincuencia a nivel nacional.

Segundo: Sabido es que, ningún régimen penitenciario mejorará por la sola optimación de la infraestructura de sus cárceles motivo por el cual, para lograr concretizar los conceptos de reinserción, reincorporación no solamente deben estar enfocados en la persona, que debe rehabilitarse para volver a la sociedad, sino que en virtud de que la finalidad de la pena se encuentra también justificada debido al beneficio para sociedad, esta ha de también someterse a un cabio profundo que permita una armonización concatenada. 
En síntesis, se requiere la existencia de un movimiento centrípeto, tanto de la población carcelaria como de la sociedad.

\section{BIBLIOGRAFÍA}

Acosta Gallegos, C. (s.f.). Bases para una politica criminal alternativa. Universidad Mayor de San Marcos, 1-14.

Baratta, A. (2004). Criminlogóa Crítica y Crítica al Derecho Penal. Buenos Aires: Siglo Veintiuno.

Busato, P., \& Montes Huapaya, S. (2009). Introducción al Derecho Penal "Fundamentos para un sistema penal democratico". Managua: Servicios Gráficos.

Cárcamo, E., Guarnizo, A., Mendoza, M., Pajares, C., \& Vignolo, G. (2015). Asociacionespúblicos-privadas en elsistema penitenciario, una alternativa de solución para la inseguridad en el Perú. Lima: Digital S.A.

Castillo Torres, P. (s.f.). El derecho de los reclusos y sentenciados a ocupar establecimientos adecuados. 1-5.

Castro Vadillo, N. J. (2009). Realidad Penitenciaria y Derechos Humanos:Penal de Lurigancho Perú. Santa Lucía de la Rábida: Universidad Internacional de Andalucía.

Defensoría del Pueblo. (2020). Situación de las personas privadas de libertad a propósito de la declaratoria de emergencia sanitaria. Lima: Informes Especiales No 03-2020 DP.

Grandez Rojas, C. (2017). Derecho penal del enemigo y la politoca criminal en el Perú. Lambayeque: Tesis doctoral.

Gusis, G., Erbetta, D., Espina, N., Simas, L., Slokar, A., Tenorio, F., \& Zaffaroni, E. (2020). Morir de cárcel "Paradigma jushumanistas desde el virus de nuestro tiempo". Buenos Aires: Sociedad Anónima, Editora Comercial, Industrial y Financiera.

INPE. (2018). Manual de Derechos Humanos aplicados a la función penienciaria. Lima: Punto y Grafía S.A.C.

INPE. (Marzo de 2020). Informe Estadistico. Lima: Oficina de Planeamiento y Presupuesto.

Martínez Blanch, P. (2014). La resocialización del delicuente. Castillo de la Plata: Universidad Jaume I.

Pérez Guadalupe, J. L. (2009). Las Victimas y la Pastoral Penitenciaria de América Latina. Eguzkilore, 59-78.

Tribunal Constitucional. Sentencia N. ${ }^{\circ}$ 01134-2020-PHC/TC (M.TC. Ledesma Narváez, Ferrero Costa, Miranda Canales, Blueme Fortini, Ramos Núñez y Sardón de Taboada: Junio 18 de 2020)

Tribunal Constitucional. Sentencia N. ${ }^{\circ}$ 01425-2002-HC/TC (M.TC. Rey Terry, Revoredo Marsano, Alva Orlandini, Bardelli Lartirigoyen, Gonzales Ojeda y García Toma: Agosto 01 de 2002)

Zaffaroni, E. (2020). Penas ilicitas un desafío dogmático penal. Buenos Aires: Editores del Sur.

\section{INFORMACIÓN ADICIONAL}

Investigación formativa realizada por: Estudiantes del curso de Criminología de la Escuela Profesional de Derecho de la Facultad de Ciencias Jurídicas y Políticas de la Universidad Nacional del Altiplano Puno. 